\title{
Educators as Authors: Teaching Beyond the Classroom
}

\author{
Deanna Marie Pecaski McLennan
}

Published online: 27 October 2012

(C) Springer Science+Business Media New York 2012

\begin{abstract}
This article discusses why educators might consider writing and submitting papers for consideration of publication in professional journals and magazines. A general overview of teachers' challenges to the writing process and corresponding responses is provided.
\end{abstract}

Keywords Writing - Research - Author - Reflection . Practice $\cdot$ Collaboration

Writing is easy. You just sit at the typewriter and open a vein, and read it out one drop at a time. (Smith 1986).

The sound of laughter and glasses clinking set the tone for the evening's gathering. The approaching winter break had everyone in jolly spirits and the audience was warmly receptive to the speaker. She began with a quick smile and in a clear, crisp voice, shared the quote above. Many of the teachers nodded in agreement and the low murmur of whispering ceased as they turned their full attention toward her. The holidays usually brought a respite from the daily grind of education, but for these teachers it would provide much needed time to reflect upon their best practices and learn how to share them with others in a publishable format. The evening was focused on providing information and support for those interested in the grueling task of writing and submitting a manuscript to a journal. Although publishing is not typically viewed as part of the job, these teachers felt that they had important and engaging ideas

D. M. Pecaski McLennan $(\square)$

Elementary Educator with the Greater Essex County District

School Board, Ontario, Canada

e-mail: deannaandtrevor@sympatico.ca;

deannapecaskimclennan@yahoo.ca that others might find useful. The workshop was organized to help each teacher craft a paper from draft to publication. This assembly sought to provide the mentorship, time, and assistance necessary to help disseminate the research and innovative practices that were occurring in educational spaces.

Although many teachers engage in larger scale projects as part of a graduate degree, subject specialist program, or research grant, their colleagues are often unaware of this work and are therefore unable to implement these ideas and transform their practice (Dixon 2001). According to Robertson and Webber (2002) there exists a disconnect between theory and practice that prevents access to one another's work in education, often requiring innovation in thinking in order to cross the various divisions that exists between teachers, schools, and organizations.

As a fellow educator, I was invited to speak to the group of teachers based on my experience publishing. After completing my doctorate a few years ago I turned to writing as a method of professional development and connection to others; helping me deepen my understandings of the events occurring in my kindergarten classroom, and share my insights on my evolving pedagogy and practice. Educational writing and publishing allows us to deeply examine our long-held beliefs and share them with the world, and for me this process often conjured feelings of great excite for, belief in, and passion about the topic at hand (Jalongo 2002). When I am in the middle of a paper it consumes me. It's what I think of in those precious empty moments before falling asleep at night or while waiting in line at the grocery store, and it's the first thing I do whenever I have an hour or two to spare. It defines who I am as a person and teacher. Henson (2003) reminds us that most educators teach what they love and enjoy engaging with others interested in the same: 
When you have an important insight and you have crafted an effective method of sharing it in your classes, few moments are as rewarding as the moment when students connect this new knowledge with their prior understanding. Writing a professional article can help make this connection happen more often in your classes. (p. 789)

Many months after the initial writing workshop a colleague approached me. Although her paper was still in its infancy, she spoke of how writing over the winter evoked a paradigm shift in her practice. Committing ideas to paper in order to explain the inner workings of her classroom had enabled her to view the program through a new lens. Realizing this allowed her to consider the interests and needs of her students, resulting in many changes in her teaching for the betterment of her students. Her divisional partners had taken an interest and had also attempted some of the strategies explored in her work. Had this teacher not undertaken the writing project, her classroom (and many others) might still be in a static state similar to many years of past practice. Writing was the catharsis she needed to move forward in her personal professional development.

\section{Why Don't More Educators Write?}

After our encounter I wondered why teachers didn't engage in writing opportunities more often. Reading seemed to be a natural part of our professional development (e.g. book clubs, journal subscription, blogs) yet writing was often overlooked as equally important self-reflective behaviour. I concluded that there existed a perception that writing and publishing papers was a daunting task. Many educators wanted to write, yet felt they didn't know how to gather ideas worthy of publishing or what to do with their paper once finished. Henson (2005) reminds us that publishing is not about how smart or accomplished one is in his or her respective field-it's about feeling passionate about your area and making writing about it an ongoing part of one's professional life. Finding another teacher interested in the same subject area may be just the spark needed for reluctant writers. Writing together with a more experienced colleague or mentor-teacher will be more enjoyable, help you meet deadlines, and offer you more opportunities for idea sharing (Parsons 2011).

Another reason why many educators might not write is due to the lack of time they have in their demanding schedules. Increasing initiatives and professional obligations are being included as part of one's educational duties (e.g. extra curricular activities, professional learning communities, standardized test preparation, gaining additional qualifications), leaving educators with less time and autonomy to focus on self-identified areas of professional interest and development. With more and more educators struggling to find a work-life balance, writing about work during one's off time may not be appealing to many. Given that writers are rarely paid for their material, and often lose the copyright to their work once it's published, there is little monetary or social motivation for teachers to write in their personal time. This stands in contrast to their postsecondary colleagues who often utilize their publications as fodder for speaking engagements, or as a tool for securing tenure and promotion.

\section{Becoming Inspired to Write}

If writing and publishing lack social or financial merit, then why would educators consider doing so? Like the above teacher who was inspired by her experiences in the writing workshop, research shows that many educators find great satisfaction in sharing their work with others and view publishing as an opportunity to develop and sustain collective knowledge and development. It can enhance the role and status of educators, elevating them as professionals and knowledge creators in their area of expertise (Henson 2007; Shteiman et al. 2010). In a recent editorial Gardiner (2008) wondered why teachers looked to university scholars and not their same subject or grade peers for advice even though teachers "test, modify, and clarify lessons every day in the most important research lab we have" producing a "treasure chest full of ideas" (p.760). He suggested that teachers do not easily communicate with others outside of their school and have the professional obligation of sharing their ideas on a larger scale through publication. By doing so they become empowered in their practice and perhaps feel even more passionately about what they do. They begin to see themselves as transformers of education and this elevates their status in a world of academia. Active, reflexive writing aids teachers in constructing higher levels of knowledge and understanding regarding their personal teaching and learning (Hoover 1994), directly benefiting students, their families, and other educational stakeholders. Writing about the classroom may serve as great inspiration for continuing to evolve one's practice. Henson (2003) states:

Writing for publication should never be separate from our teaching. By choosing to research and write about those topics that we teach, we can allow our publishing to enrich our classes by increasing the depth of our class discussions and keeping us current in our fields (p. 788).

Writing also may help educators fulfill some of the professional obligations that they have as part of their 
profession. For example, in some areas educators are required to submit an 'Annual Learning Plan' in order to outline their plans for professional development for the year. Including writing as part of professional learning plans or teacher performance appraisal will help satisfy job requirements, and provide educators with the time, resources, and support necessary to do so.

\section{Moving Towards Authorship}

Before writing any paper, one needs an idea of where to start. I consider myself just as much a writer as I am an educator, and so I look for inspiration in everyday events at school and home. When I am not actively working on a paper I engage in a number of writing behaviours that help me to gather ideas, shape my understandings of events, and transform this into knowledge that I can share with others. These activities include:

- $\quad$ using a writing $\log$ to continuously record interesting ideas, inspirational quotes or facts, and rough outlines of papers before I'm ready to commit to writing them. I often keep a reflective journal in my daybook and jot down ideas at the end of each day-what worked well in my lessons, what could be improved, and any 'ah ha' moments that occurred.

- engaging in professional conversations with colleagues at professional development opportunities in order to clarify information and reach shared understandings with others. I attend many events in my field with the same educators and we often engage in deep discussions about our current practices and how they are evolving based on our changed understandings as a result of our new learning-these could easily be shaped into papers.

- reading current journals in order to learn about new issues in education, reflect upon current practice, and gather current and relevant research in order to support skeletal ideas for projects. I subscribe to a number of professional publications and these have become venues for pursuing publication as well.

- collaborating with a more experienced colleague like a university professor or administrator who has experience writing and publishing and can act as a mentor. I like to work with a colleague when I am unsure of exactly how to proceed with a paper, or need some extra guidance and motivation.

- exploring ideas and events with divisional teaching partners as shared research and writing exists as a natural extension of our collaborative education activities. Because we are required to present new classroom practices with our school staff, my teaching partners and I have explored turning these into publishable papers.

- evolving workshops and presentations I've taken the time and effort invested into planning a workshop and converted it into a written paper that can be shared with a wider audience.

\section{Deciding Exactly What to Write}

Although my papers have been varied in topic and form, they all share one thing-I have felt much passion for what it is I have written about. Once a paper is published there is a possibility that (hopefully) thousands of people will be reading it! Therefore an author must have a great love of the paper and be ready to discuss, debate, and sometimes defend the ideas presented within. Regardless of whether the intended audience is going to be scholarly or less formal, there are many options for educators hoping to delve into the writing experience to choose from including:

- opinion or editorial pieces that are similar to argumentative essays where a particular position is strongly presented and defended through the citing of references and personal experiences in the hopes of informing policy and practice. I have found that writing these types of pieces to be an effective and cathartic way to express my ideas when current policy and practice differ from what I believe in professionally.

- descriptions of innovative practice include overviews of exciting activities that are happening in a variety educational environments in hopes of providing practical ideas that will inspire others. When visitors to our classroom comment on aspects that appeal to them, it inspires me to share what is working for us with a greater audience.

- research reviews are methodological descriptions of empirical research and may be the result of a rigorous qualitative or quantitative investigation as part of a research project such as a Master Thesis or Doctoral Dissertation. Many educators complete these degrees but do not consider publishing their research.

- special interest articles are usually about a central theme or interest and a 'call for authors' and deadline are usually communicated by the publication. For those educators who have a specialty, these might be the perfect venue for sharing.

- book reviews contain a description, analysis, and evaluation of a text's strengths and weaknesses in order to inform potential readers of the work. Many educators engage in professional reading, especially over long holidays like the summer. Reviewing what 
has been read is a natural extension and an easy way to delve into the world or writing and publishing.

\section{Conclusion}

There are a few of us from that original workshop that still meet to discuss shared interests and work together on projects. Writing has become as engrained into our very beings as educators as lesson planning or communicating with the families of our students. Although the job of a teacher often seems never-ending, our group considers writing to be an extension of the teaching that occurs in our classrooms as we support one another through our projects. It's yet another way we can help transform the world around us, and better the lives of the children in our care. When we share our educational philosophies and best practices with others in a published format, we are helping to improve the state of education, one reader at a time. Like a pebble skipping on the water's surface, the effects of our shared knowledge makes ripples that extend far beyond the confines of our classroom walls-one word at a time.

\section{References}

Dixon, N. (2001). Writing for publication: A guide for new authors. International Journal for Quality in Health Care, 13(5), 417-421.

Gardiner, S. (2008). Teachers need to share their ideas. Phi Delta Kappan, 89(10), 760-761.

Henson, K. T. (2003). Writing for professional publication: Some myths and some truths. Phi Delta Kappan, 84(10), 788-791.

Henson, K. T. (2005). Writing for publication: A controlled art. Phi Delta Kappan, 86(10), 772-781.

Henson, K. T. (2007). Writing for publication. Phi Delta Kappan, 88(10), 781-786.

Hoover, L. (1994). Reflective writing as a window on preservice teachers' thought processes. Teaching and Teacher Education, 10(1), 83-93.

Jalongo, M. R. (2002). Writing for publication: A practical guide for educators. Norwood, MA: Christopher-Gordon Publishers, Inc.

Parsons, J. (2011). Tips for successful reading, writing, and publishing in academia. Christian Education Journal, 8(2), 410-415.

Robertson, J. M., \& Webber, C. F. (2002). Boundary-breaking leadership: A must for tomorrow's learning communities. In K. Leithwood \& P. Hallinger (Eds.), Second international handbook of educational leadership and administration. Amsterdam, The Netherlands: Kluwer.

Shteiman, Y., Gidron, A., Eilon, B., \& Katz, P. (2010). Writing as a journey of professional development for teacher educators. Professional Development in Education, 36(1/2), 339-356.

Smith, R. (1986). National Public Radio [Interview]. Washington, DC. 